\title{
Colony Stimulating Factor Signaling Process
}

National Cancer Institute

\section{Source}

National Cancer Institute. Colony Stimulating Factor Signaling Process. NCI Thesaurus.

Code $\mathrm{C} 40585$.

Any process which promotes expression of colony stimulating factors, their subsequent secretion, binding to their cognate receptors or intracellular signaling, and results in proliferation and differentiation of the targ et cell. This process is involved in regulating active populations of macrophages, granulocytes and myeloid cells. 